\title{
Systematic review and meta-analysis of ethnic differences in risks of adverse reactions to drugs used in cardiovascular medicine
}

\author{
Sarah E McDowell, Jamie J Coleman, R E Ferner
}

\begin{abstract}
Objective To review the evidence for ethnic differences in susceptibility to adverse drug reactions (ADRs) to cardiovascular drugs.

Design Systematic review and meta-analysis.

Data sources We searched Medline and Embase to March 2005. Reference lists of identified articles were hand searched for further relevant articles.

Review methods Studies were eligible for inclusion if they included at least two ethnic groups and one or more ADRs. We excluded case reports and case series.

Results 564 studies contained some description of ethnicity and an ADR, and 132 of them related to cardiovascular therapies. Twenty four studies provided data for ADRs for at least two ethnic groups and were therefore eligible for inclusion. In pooled analyses the relative risk of angio-oedema from angiotensin converting enzyme (ACE) inhibitors in black compared with non-black patients was 3.0 (95\% confidence interval 2.5 to 3.7); the relative risk of cough from ACE inhibitors was 2.7 (1.6 to 4.5) in East Asian compared with white patients; and the relative risk of intracranial haemorrhage with thrombolytic therapy was 1.5 (1.2 to 1.9$)$ in black compared with non-black patients.

Conclusion Patients from different ethnic groups have different risks for important ADRs to cardiovascular drugs. Ethnic group may therefore be one determinant of harms of a given treatment in the individual patient, either because it acts as a surrogate measure of genetic make up or because cultural factors alter the risk. Data are sparse, and regulators should consider asking for better data before licensing.
\end{abstract}

\section{Introduction}

Adverse drug reactions (ADRs) cause considerable morbidity and mortality and an increased burden on the healthcare system, accounting for about $6.5 \%$ of acute hospital admissions. ${ }^{1-3}$ They can be classified according to dose relatedness, time, and patient susceptibility (DoTS). ${ }^{4}$ Genetic make up, age, sex, physiological changes, exogenous factors such as coprescribed drugs or diet, and disease state can all alter a patient's susceptibility to ADRs. ${ }^{5-10}$

There is no consensus on the relation between genetics and ethnic or racial classifications. ${ }^{11-17}$ Some have argued that ethnic and racial labels are poor biological proxies for underlying genotype, ${ }^{12}{ }^{16}$ but ethnic classification could still account for complex interactions between genetics, environment, society, and other factors. ${ }^{14}$ Some drugs have been shown to be more effective in certain ethnic groups ${ }^{18}{ }^{19}$ and isosorbide dinitrate plus hydralazine (BiDil) has been recently licensed in the United States specifically for use in black patients. ${ }^{20}$

It is not known to what extent susceptibility to ADRs might depend on ethnic group, whether as a result of genetic or cultural factors. We therefore undertook a systematic review of reported associations between increased susceptibility and ethnicity. When possible we used meta-analysis to estimate the quantitative effect of ethnic differences on the risk of adverse reactions to drugs.

\section{Methods}

\section{Search strategy}

In March 2005 we searched Medline (from 1951) and Embase (from 1974), without any language restriction, using relevant text words and search terms to find papers containing both a description of ethnicity and ADRs in adults, excluding case reports or case series (see appendix 1 on bmj.com).

\section{Selection of studies}

Two reviewers (JJC and SEMcD) independently reviewed the title and abstract of all identified studies, using the following inclusion criteria: there was mention of ethnicity, ethnic groups, or racial groups and there was a description of an experiment specifically to investigate $\mathrm{ADRs}$ or of $\mathrm{ADRs}$ that were a result of drug treatment.

A third reviewer (REF) examined studies initially identified for inclusion by only one person. Studies selected by any two reviewers were retained, and where an $\mathrm{ADR}$ was described, the relevant drug was classified using the classification in British National Formulary (No 49) in which cardiovascular drugs are assigned to chapter $2 .{ }^{21}$ We obtained full text copies of studies referring to drugs from chapter 2 . We included studies if they contained data comparing at least two ethnic groups for a specified ADR. We hand searched included studies to identify further relevant research and approached the authors of studies that suggested they might have relevant numerical data not included in the published papers.

We assessed each study for selection bias, performance bias, attrition bias, and detection bias. ${ }^{22}$ We scored each study according to whether there was a low, moderate, or high risk of each of the four biases to provide an overall judgment of study validity and quality.

\section{Data analysis}

We used a standard form to extract discrete data for analysis from included studies (see appendix 2 on bmj.com). Authors did

References to included trial (w1-w24), details of the search strategy, the data extraction form, and classification of ethnicity can be found on bmj.com. 


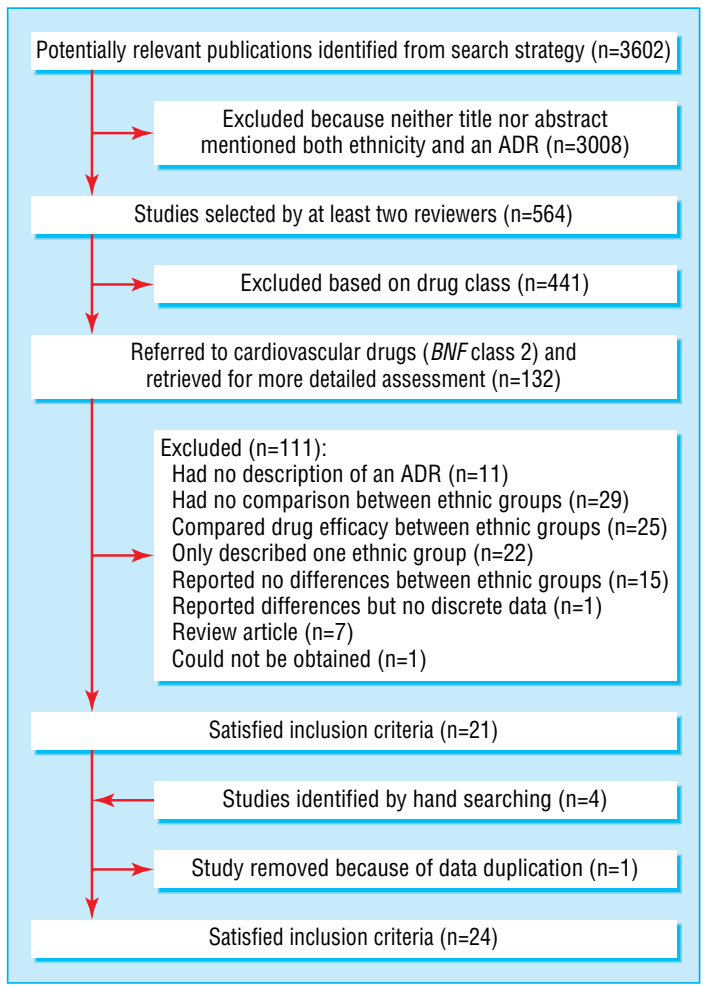

Fig 1 Flow chart of study selection

not generally describe how ethnic or racial classifications were assigned so we extracted data for the ethnic groups as described in each paper. Terms to describe ethnicity varied widely and to present the data using consistent terminology we used the terms black, East Asian, South Asian, and white. ${ }^{23}$ Black patients were compared with patients who were predominantly white, but this sometimes included patients categorised as Hispanic or Latino; Asian, East Asian, non-East Asian, or Pacific Islander; Native
American; or "other." We labelled these heterogeneous groups as "non-black" (see appendix 3 on bmj.com).

We estimated heterogeneity among studies grouped according to drug class and ADR by the $\chi^{2}$ test and $\mathrm{R}(I)$ statistic. ${ }^{24}$ Data were pooled by means of a fixed effects model if heterogeneity was absent, otherwise by means of a random effects model. ${ }^{25} \mathrm{We}$ used Revman 4.2.7 (Oxford, UK) for these analyses.

\section{Results}

The initial search strategy retrieved 3602 studies. Of these, two reviewers selected 564 studies for further analysis, of which 132 referred to cardiovascular drugs. We failed to obtain one study (fig 1). Twenty four studies fulfilled all our criteria (full details can be found at www.csmwm.org/pdf/BMJ_ethnicity_studies.pdf).

\section{Angiotensin converting enzyme inhibitors}

Angio-oedema-Six studies considered angio-oedema due to angiotensin converting enzyme (ACE) inhibitors. ${ }^{\text {w1-w6 }}$ We excluded one small clinical study as it was classified as being at high risk of bias. ${ }^{\mathrm{w} 5}$ Pooled analysis of unadjusted data from five studies using the fixed effects model found that black patients had a relative risk of angio-oedema of 3.0 (95\% confidence interval 2.5 to 3.7) compared with non-black patients (fig 2).

Cough-Two studies presented data comparing incidence of cough due to ACE inhibitors between East Asian (Chinese, Korean, or Japanese) and white patients. ${ }^{\mathrm{w}}{ }^{\mathrm{w} 8}$ The pooled relative risk calculated from the unadjusted data was 2.7 (1.6 to 4.5) (fig 3). Pooled analysis of the unadjusted data from three studies, using the random effects model, gave a non-significant relative risk of 1.1 (0.5 to 2.3) of cough due to ACE inhibitors in black compared with non-black patients (fig 4). ${ }^{\mathrm{w} 7 \mathrm{w} 9 \mathrm{w} 10}$ We excluded a fourth study because we thought it had a high risk of potential bias. ${ }^{\text {w11 }}$

\section{Thrombolytic therapy}

Intracranial haemorrhage-Two studies reported data on intracranial haemorrhage in patients treated with thrombolytic

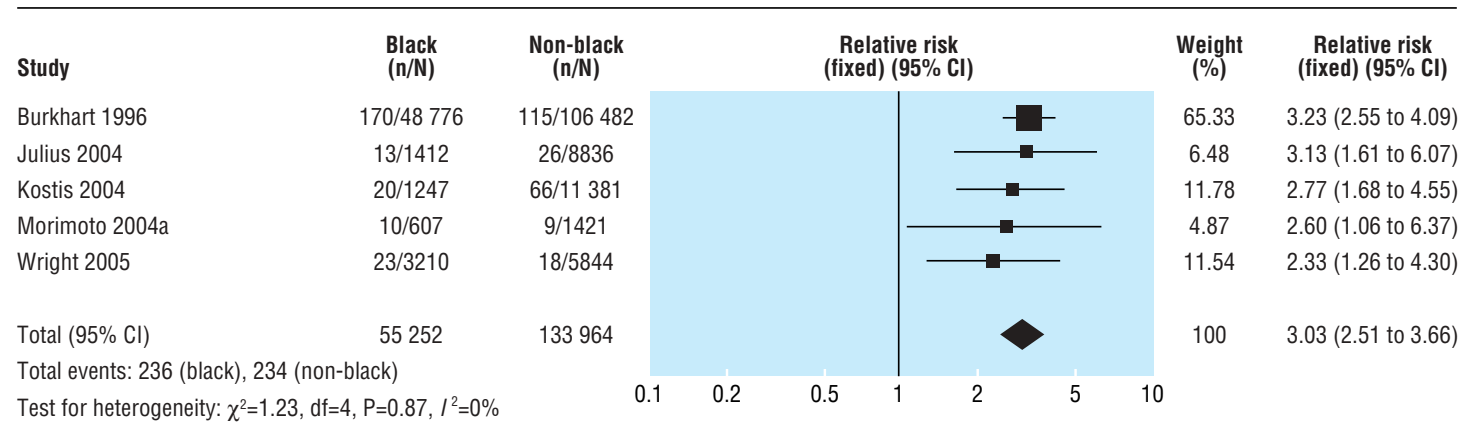

Fig 2 Pooled analysis of proportion of black and non-black patients with angio-oedema associated with use of ACE inhibitors

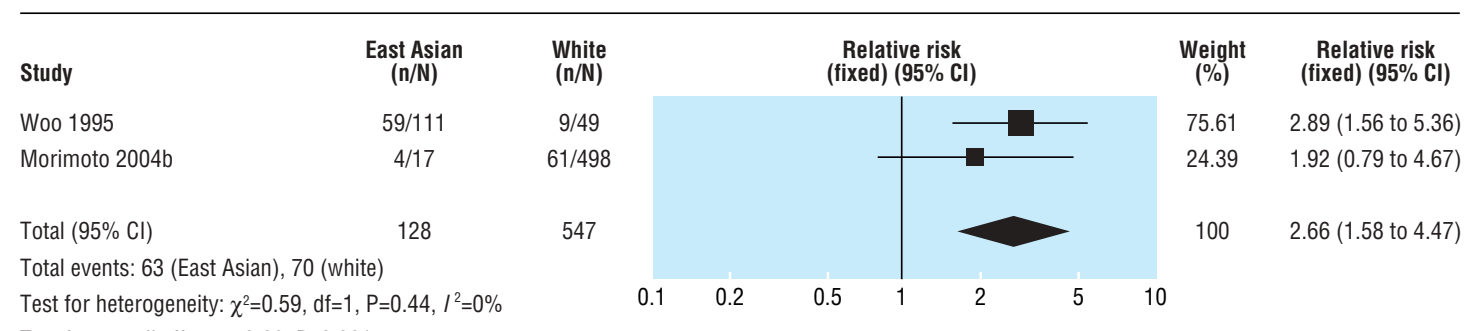

Fig 3 Pooled analysis of proportion of East Asian and white patients with cough associated with use of ACE inhibitors 
therapy. ${ }^{\mathrm{w} 12 \mathrm{w} 13}$ The risk of intracranial haemorrhage was higher in black patients than non-black patients (unadjusted pooled relative risk $1.5,1.2$ to 1.9 ) (fig 5).

Moderate or severe bleeding-The GUSTO-1 study reported that black patients were at increased risk of moderate or severe bleeding after treatment with thrombolytic treatment (adjusted odds ratio $1.9,1.6$ to 2.3 ). ${ }^{\text {w1 } 14}$ About $17 \%$ of black patients experienced moderate to severe bleeding compared with $11 \%$ of nonblack patients.

\section{ADRs associated with other types of drug treatment}

Four studies described ADRs associated with the use of antihypertensive drugs. A small clinical trial reported significantly more depression with hydrochlorothiazide in black patients than in white patients. ${ }^{\text {w15 }}$ A prospective study, using a different measure, described a subtle difference in depression scores between black and white patients treated with antihypertensive drugs. ${ }^{\mathrm{w} 16}$ A small randomised controlled trial noted that the proportion of black patients reporting headache was nearly $17 \%$ compared with just over $2 \%$ in non-black patients $(\mathrm{P}<0.05){ }^{\mathrm{w} 17}$ Finally, retrospective analysis of medical records by Hui and Pasic found that 26\% of East Asian patients (defined as Chinese, Japanese, Filipino, Korean, and other) reported adverse effects associated with antihypertensive drugs, compared with $13 \%$ of white patients $(\mathrm{P}<0.002) .{ }^{\mathrm{w} 18}$ The authors did not describe the adverse effects.

One prospective study reported non-white race (defined as black, Hispanic, or other) as a risk factor for admission to hospital because of bleeding after oral anticoagulant treatment for deep vein thrombosis (hazard ratio 1.6, 1.2 to 2.1). ${ }^{\text {w19 }}$ Black patients were also found to have an increased risk of admission with an adverse event associated with digitalis treatment compared with white patients (odds ratio 1.37, 1.35 to 1.39).w20

Morales and colleagues compared the prevalence of adverse effects with simvastatin from two clinical trials undertaken in East Asian (China, Hong Kong, Korea, Taiwan, Thailand) and non-East Asian countries. ${ }^{\text {w21 }}$ No difference was found in the proportion of patients experiencing either a clinical or laboratory adverse effect.
A small clinical trial studied 58 patients who were treated with intravenous ibutilide (an anti-arrhythmic agent not licensed in the United Kingdom) because of recent onset of atrial fibrillation and atrial flutter. ${ }^{\mathrm{w} 22}$ Three of 20 black patients developed torsade de pointes after treatment compared with one of 38 non-black patients $(\mathrm{P}=0.077)$.

No significant difference was observed in the ethnic or familial distribution of the patients presenting with respiratory disease exacerbated by aspirin, a clinical syndrome characterised by chronic rhinitis, nasal polyps, asthma, and precipitation of asthma and rhinitis attacks. ${ }^{\mathrm{w} 3}$

One large, open label clinical trial monitored patients for 10 specific ADRs to pindolol, a $\beta$ adrenoceptor antagonist. ${ }^{\mathrm{w} 24}$ White patients reported a greater number of adverse effects than black patients for each ADR that was monitored, though these differences were not significant.

\section{Discussion}

The 24 studies we looked at provided unique data for adverse reactions to cardiovascular drugs for different ethnic groups. Our analysis supports the contention that ethnicity may predict differences in susceptibility to ADRs to cardiovascular drugs. Ethnic differences in susceptibility to ADRs of angiotensin converting enzyme inhibitors are evident and consistent with those from studies in single ethnic populations that describe a high incidence of angio-oedema in black patients, ${ }^{26}$ and cough in East Asian $^{27-29}$ and black patients. ${ }^{30}$

Susceptibility to adverse drug reactions is influenced by factors such as age, sex, and disease state. Some of the genetic factors that are believed to affect response to drugs, such as cytochrome P450 (CYP) genotype, are distributed differently in different ethnic groups. For example, two CYP2C9 alleles that result in poor metabolism have been found to occur in $11 \%$ and $8 \%$ of white individuals but only in $3 \%$ and $0.8 \%$ of black individuals. ${ }^{19}$ This has important implications for clinicians because CYP2C9 is responsible for the metabolism of warfarin and individuals with poor metabolism may therefore require lower doses. ${ }^{6}$ The relation between genetic make up, ethnicity,

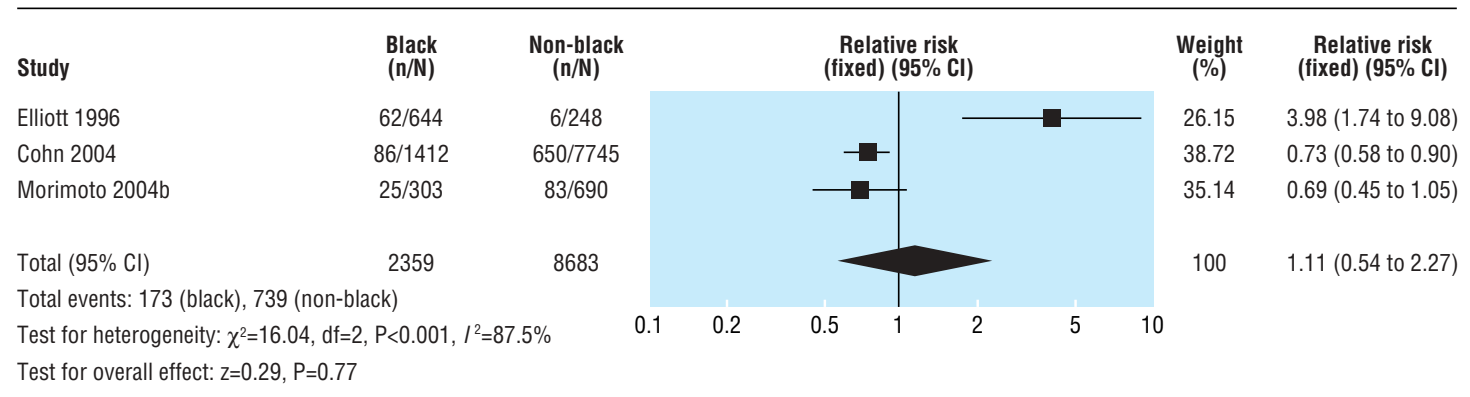

Fig 4 Pooled analysis of proportion of black and non-black patients with cough associated with use of ACE inhibitors

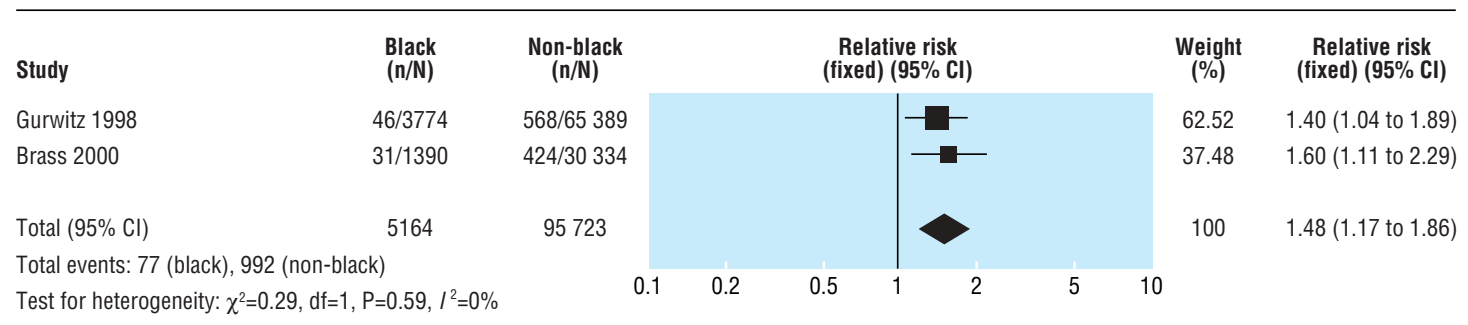

Test for overall effect: $z=3.31, P<0.001$

Fig 5 Pooled analysis of proportion of black and non-black patients with intracranial haemorrhage associated with thrombolytic treatment 
and effects of drug is less clear, though the benefits of drug treatment have been shown in one ethnic group but not in another. ${ }^{31} 32$

Our results need to be interpreted cautiously for several reasons. The included studies differed in quality and did not report either ADRs or ethnicity consistently, which made synthesis of results between studies difficult. Data on ADRs are often not presented or are dismissed in vague terms such as "the drug was well tolerated" or "there were no significant differences between ADRs." Even when data on harms are reported, they are often presented for only one treatment arm or are aggregated, making it impossible to find data on specific ADRs. Studies may have been omitted from our review by the inadequate and inconsistent reporting of ADRs in the literature ${ }^{33} 34$ or because our search strategy failed to identify relevant papers. Though we used a broad search strategy that used a combination of indexing terms and text words, literature searches may fail to identify studies that do actually report on rates of ADRs. ${ }^{35}$

We excluded many studies because only data on efficacy, and not safety, were presented by ethnic group. Most studies that reported ADR data for different ethnic groups failed to describe how ethnicity was classified, thus limiting the comparison between different studies. When data were available, we sometimes combined ethnic groups to investigate the association between ethnicity and susceptibility to ADRs. This may have obscured differences within larger ethnic groups and thus limited the generalisability of the results. Consistent and transparent descriptions of assignments to well defined ethnic groups are needed. ${ }^{3637}$

\section{Bias and confounding}

The data must also be interpreted cautiously because of the risk of publication bias. Studies that reported differences in ADRs between ethnic groups may have been more likely to publish such data than studies that found no such difference or where safety analysis was not the primary focus of the project. This may have resulted in an overestimate of the risk of certain ethnic groups experiencing specific ADRs.

The included studies lacked data on possible confounding factors such as age, sex, or severity of illness by ethnic group and so we could not adjust for these. They have been shown to independently affect the risk of developing an ADR and thus may have resulted in an overestimate of the true association between ethnicity and increased susceptibility to ADRs.

Finally, we did not look outside the published literature and so excluded data from unpublished drug trials and conferences. While manufacturers may hold relevant data, they are often not in the public domain. Finally, our search strategy was not designed to include studies that reported rates of ADRs in single ethnic populations because such studies necessarily rely on comparisons with other populations at different times and by different methods. This may have excluded possibly relevant information.

\section{Conclusions}

The goal of rational drug treatment is to maximise benefits or the chance of benefit and to minimise harm or the risk of harm. We have provided relative frequencies of ADRs in different populations that suggest the risk of harm may vary with ethnic group and may help the clinician present more accurate and relevant data to their patients when prescribing therapy. When ethnic differences in susceptibility exist, they may act as a marker for potentially important genetic or environmental factors that can influence the balance between benefit and harm and help to direct future research. This will be possible only through increased recruitment of individuals from different ethnic groups and when pharmaceutical companies report data on ethnicity routinely in the analyses of clinical trials. Furthermore, it is essential that future studies explicitly describe how the classification of ethnic group was achieved and the relevance of ethnicity to the study. This will allow for greater consistency of results and improved comparison between studies.

Our results illustrate that, for a small but well defined set of cardiovascular drugs, and a small number of ethnic groups, there is evidence that susceptibility to adverse reactions differs between ethnic groups. For a much larger group of drugs, the data do not exist to confirm or refute the existence of ethnic differences in susceptibility to ADRs.

We are grateful to Christopher Hyde, University of Birmingham, for helpful comments on a draft of this paper.

Contributors: SEMcD participated in the design of the search strategy, carried out the literature searches, applied inclusion criteria, extracted data, and contributed to the writing of the text. JJC had the idea for the review, carried out the literature searches, applied inclusion criteria, and contributed to the writing of the text. REF had the idea for the review, supervised the conduct of the study, participated in the design of the search strategy, acted as an arbitrator during study selection, contributed to the writing of the text, and is guarantor.

Funding: SEMcD was supported by the Antidote Trust Fund of the Sandwell and West Birmingham Hospitals NHS Trust.

Competing interests: None declared.

Ethical approval: Not required.

1 Bates DW, Spell N, Cullen DJ, Burdick E, Laird N, Petersen LA, et al. The costs of adverse drug events in hospitalized patients. Adverse Drug Events Prevention Study Group. JAMA 1997:277:307-11.

2 Bates DW, Cullen DJ, Laird N, Petersen LA, Small SD, Servi D, et al. Incidence of adverse drug events and potential adverse drug events. Implications for prevention. ADE Prevention Study Group. JAMA 1995:274:29-34.

3 Pirmohamed M, James S, Meakin S, Green C, Scott AK, Walley TJ, et al. Adverse drug reactions as cause of admission to hospital: prospective analysis of 18820 patients. BMJ 2004;329:15-9.

4 Aronson JK, Ferner RE. Joining the DoTS: new approach to classifying adverse drug reactions. BMJ 2003;327:1222-5.

5 Phillips KA, Veenstra DL, Oren E, Lee JK, Sadee W. Potential role of pharmacogenomics in reducing adverse drug reactions: a systematic review. JAMA 2001;286:2270-9.

6 Aithal GP, Day CP, Kesteven PJ, Daly AK. Association of polymorphisms in the cytochrome P450 CYP2C9 with warfarin dose requirement and risk of bleeding complications. Lancet 1999;353:717-9.

7 Higashi MK, Veenstra DL, Kondo LM, Wittkowsky AK, Srinouanprachanh SL, Farin FM, et al. Association between CYP2C9 genetic variants and anticoagulation-related outcomes during warfarin therapy. JAMA 2002;287:1690-8.

8 Hughes DA, Vilar FJ, Ward CC, Alfirevic A, Park BK, Pirmohamed M. Cost-effectiveness analysis of HLA B*5701 genotyping in preventing abacavir hypersensitivity. Pharmacogenetics 2004;14:335-42.

9 Bailey DG, Dresser GK. Interactions between grapefruit juice and cardiovascular drugs. Am J Cardiovasc Drugs 2004;4:281-97.

\section{What is already known on this topic}

Adverse drug reactions (ADRs) are an important cause of morbidity and mortality

Susceptibility to ADRs varies with genetic make up, age, sex, physiology, exogenous factors, and disease state

\section{What this study adds}

Some ethnic groups may be more susceptible to ADRs during treatment with angiotensin converting enzymes and thrombolytic drugs

Ethnic group may act as a marker for underlying genetic or environmental differences in this susceptibility

Studies investigating drug treatment need to report both adverse reactions and racial and ethnic classifications more fully 
10 Kempin SJ. Warfarin resistance caused by broccoli. N Engl J Med 1983;308:1229-30. 11 Bhopal R. Is research into ethnicity and health racist, unsound, or important science? BMJ 1997;314:1751-6.

12 Schwartz RS. Racial profiling in medical research. N Engl J Med 2001;344:1392-3.

13 Wood AJ. Racial differences in the response to drugs-pointers to genetic differences. N Engl J Med 2001;344:1394-6.

14 Risch N, Burchard E, Ziv E, Tang H. Categorization of humans in biomedical research: genes, race and disease. Genome Biol 2002;3(7):comment2007.

15 Burchard EG, Ziv E, Coyle N, Gomez SL, Tang H, Karter AJ, et al. The importance of race and ethnic background in biomedical research and clinical practice. $N$ Engl J Med 2003;348:1170-5.

16 Cooper RS, Kaufman JS, Ward R. Race and genomics. N Engl J Med 2003;348:1166-70

17 Tate SK, Goldstein DB. Will tomorrow's medicines work for everyone? Nat Gene 2004;36:S34-42.

18 Bjornsson TD, Wagner JA, Donahue SR, Harper D, Karim A, Khouri MS, et al. A review and assessment of potential sources of ethnic differences in drug responsiveness. J Clin Pharmacol 2003:43:943-67.

19 Xie HG, Kim RB, Wood AJ, Stein CM. Molecular basis of ethnic differences in drug disposition and response. Annu Rev Pharmacol Toxicol 2001;41:815-50.

20 Taylor AL, Ziesche S, Yancy C, Carson P, D'Agostino R Jr, Ferdinand K, et al. Combination of isosorbide dinitrate and hydralazine in blacks with heart failure. $N$ Engl J Med 2004;351:2049-57.

21 British Medical Association, Royal Pharmaceutical Society of Great Britain. British national formulary. London: BMA, RPS, 2005. (No 49.)

22 Higgins JPT, Green S. Assessment of study quality. In: Cochrane handbook for systematic reviews of interventions 4.2.4. Chichester: John Wiley, 2005 (section 6).

23 Bhopal R. Glossary of terms relating to ethnicity and race: for reflection and debate.J Epidemiol Community Health 2004;58:441-5.

24 Higgins JP, Thompson SG, Deeks JJ, Altman DG. Measuring inconsistency in meta-analyses. BMJ 2003;327:557-60.

25 Egger M, Smith GD, Phillips AN. Meta-analysis: principles and procedures. BMJ 1997;315:1533-7.

26 Gibbs CR, Lip GY, Beevers DG. Angioedema due to ACE inhibitors: increased risk in patients of African origin. Br J Clin Pharmacol 1999:48:861-5.

27 Ishimitsu T, Yagi S, Ebihara A, Doi Y, Domae A, Shibata A, et al. Long-term evaluation of combined antihypertensive therapy with lisinopril and a thiazide diuretic in patients with essential hypertension.Jpn Heart J 1997;38:831-40.
28 Woo KS, Nicholls MG. High prevalence of persistent cough with angiotensin converting enzyme inhibitors in Chinese. Br J Clin Pharmacol 1995;40:141-4

29 Chan WK, Chan TY, Luk WK, Leung VK, Li TH, Critchley JA. A high incidence of cough in Chinese subjects treated with angiotensin converting enzyme inhibitors. Eur J Clin Pharmacol 1993;44:299-300.

30 Adigun AQ Ajayi AA. Angiotensin converting enzyme inhibitor induced cough in Nigerians. West Afr J Med 2001;20:46-7.

31 Exner DV, Dries DL, Domanski MJ, Cohn JN. Lesser response to angiotensinconverting-enzyme inhibitor therapy in black as compared with white patients with left ventricular dysfunction. $N$ Engl J Med 2001;344:1351-7.

32 Carson P, Ziesche S, Johnson G, Cohn JN. Racial differences in response to therapy for heart failure: analysis of the vasodilator-heart failure trials. Vasodilator-Heart Failure heart failure: analysis of the vasodilator-heart
Trial Study Group. J Card Fail 1999;5:178-87.

33 Ioannidis JP, Lau J. Completeness of safety reporting in randomized trials: an evaluation of 7 medical areas. JAMA 2001;285:437-43.

34 Loke YK, Derry S. Reporting of adverse drug reactions in randomised controlled trials-a systematic survey. BMC Clin Pharmacol 2001;1:3.

35 Derry S, Kong LY, Aronson JK. Incomplete evidence: the inadequacy of databases in tracing published adverse drug reactions in clinical trials. BMC Med Res Methodol 2001;1:7

36 Winker MA. Measuring race and ethnicity: why and how? JAMA 2004;292:1612-4.

37 International Committee of Medical Journal Editors. Uniform requirements for manuscripts submitted to biomedical journals: writing and editing for biomedical publication. Updated October 2005. www.icmje.org/\# prepare (accessed 9 December 2005).

(Accepted 23 February 2006)

doi $10.1136 /$ bmj.38803.528113.55

West Midlands Centre for Adverse Drug Reaction Reporting, City Hospital, Birmingham B18 7QH

Sarah E McDowell research officer

R E Ferner director

Department of Clinical Pharmacology, University of Birmingham, Birmingham B15 2TH

Jamie J Coleman specialist registrar in clinical pharmacology

Correspondence to: R E Ferner r.e.ferner@bham.ac.uk 